\title{
Supervision During Rehabilitation Programme Following Anterior Cruciate Ligament Reconstruction: A Systematic Review of Literature
}

\section{Supervision während des Rehabilitationsprogramms nach Ersatzplastik des vorderen Kreuzbands: Eine systematische Literaturübersicht}

\author{
Authors \\ H. Darain ${ }^{1}$, S. Z. A. Shah², F. Muhammad ${ }^{3}$, A. Al-kitani \\ Affiliations \\ ${ }^{1}$ Institute of Physical Medicine and Rehabilitation, Khyber Medical University, Peshawar, Pakistan \\ ${ }^{2}$ Physiotherapy, Rehman Medical Institute, Peshawar, Pakistan \\ ${ }^{3}$ NSC, Health Sciences, Peshawar, Pakistan \\ ${ }^{4}$ Department of Testing and Performance Enhancement, Ministry of Sports, Muscat, Oman
}

Key words
rehabilitation
anterior cruciate ligam
supervision
Physiotherapie
Physical medicine
Schlüsselwörter
Rehabilitation
vorderes Kreuzband
Physiotherapie
physikalische Medizin

received: $\quad$ 11.04.2016 accepted: $\quad$ 16.08.2016

Bibliography DOI http://dx.doi.org/ 10.1055/s-0042-115479 Phys Med Rehab Kuror 2016; 26: 225-229

(c) Georg Thieme Verlag KG Stuttgart · New York ISSN 0940-6689

\section{Correspondence}

Dr. H. Darain, PhD, MSc, BSPT Institute of Physical Medicine and Rehabilitation

Khyber Medical University

Hayatabad Phase V

25000 Peshawar

Pakistan

haider.kmu@hotmail.com

\section{Abstract}

$\nabla$

Background: The term 'supervision' during musculoskeletal rehabilitation programmes is frequently used in literature. However, there is lack of agreement in the literature regarding clearly defining the term 'supervision' and its components. Therefore, this review was carried out to identify components of supervision reported in clinical trial previously carried out on rehabilitation programmes following anterior cruciate ligament reconstruction and define the term clearly. Methods: A review of literature regarding supervision during rehabilitation programme following anterior cruciate ligament reconstruction was undertaken (Jan 2005 until December 2014). Searches in electronic database including AMED, BNI, CINAHL, EMBASE, Health Business Elite, HMIC, MEDLINE, and PsycINFO were carried out for supervision during anterior cruciate ligament rehabilitation. Keywords included anterior cruciate ligament, supervision, structured and unstructured rehabilitation were used to search for the literature.

Results: Inconsistencies in defining the term supervision during anterior cruciate ligament rehabilitation were found amongst the clinical trials carried out on supervision following anterior cruciate ligament reconstruction. In some clinical trials, supervision was associated with the environment where rehabilitation programme was delivered. In contrast, in other trials, supervision was associated with the number of physiotherapy sessions received by the patients in hospitals or other clinical settings included clinics.

Conclusion: Based on the findings of this review it may be concluded that supervision during rehabilitation programme following anterior cruciate ligament may be associated with a number of factors. Presences of physiotherapists during rehabilitation sessions, well-controlled environment and interaction amongst physiotherapists and patients have been reported core component for supervision.

\section{Zusammenfassung}

Hintergrund: In der englischsprachigen Literatur wird der Begriff „Supervision“ während des Rehabilitationsprogramms nach Erkrankungen des Bewegungsapparats häufig verwendet. Es besteht jedoch in der Literatur keine Einigkeit darüber, wie dieser Begriff genau zu definieren ist und welche Komponenten ausschlaggebend sind. Daher wurden für diesen Überblick Berichte von früher durchgeführten klinischen Studien zu Rehabilitationsprogrammen nach Ersatzplastik des vorderen Kreuzbands ausgewertet, um die Komponenten der Supervision benennen und den Begriff der Supervision eindeutig definieren zu können.

Methoden: Es wurde Literatur über Supervision während des Rehabilitationsprogramms nach Ersatzplastik des Vorderen Kreuzbands ausgewertet (Januar 2005-Dezember 2014). Elektronische Datenbanken, darunter AMED, BNI, CINAHL, EMBASE, Health Business Elite, HMIC, MEDLINE und PsycINFO wurden nach Supervision während des Rehabilitationsprogramms nach Ersatzplastik des Vorderen Kreuzbands durchsucht. $\mathrm{Zu}$ den Schlüsselwörtern für die Suche gehörten Vorderes Kreuzband, Supervision, strukturierte und unstrukturierte Rehabilitation.

Ergebnisse: In den klinischen Studien über die Supervision nach Ersatzplastik des vorderen Kreuzbands wurde der Begriff der Supervision während der Rehabilitation nach Ersatzplastik des vorderen Kreuzbands nicht einheitlich definiert. In manchen klinischen Studien wurde der Begriff Supervision mit der Umgebung in Verbindung gebracht, in der das Rehabilitationsprogramm durchgeführt wurde. Im Gegensatz dazu wurde in anderen Studien der Begriff Supervision mit der Anzahl der physiotherapeutischen Behandlungen verbunden, welche die Patienten im Krankenhaus oder anderen klinischen Einrichtungen erhielten. 
Schlussfolgerung: Aus den Ergebnissen dieser Literaturübersicht kann geschlossen werden, dass für die Supervision während des Rehabilitationsprogramms nach Ersatzplastik des vorderen Kreuzbands eine Anzahl verschiedener Faktoren bestimmend sein können. Die Anwesenheit von Physiotherapeuten während der Rehabilitationsbehandlungen, eine gut kontrollierte Umgebung und das Zusammenwirken von Physiotherapeuten und Patienten sind demnach wesentliche Komponenten der Supervision.

\section{Introduction}

Anterior cruciate ligament (ACL) is one of the commonest musculoskeletal injuries affecting a large proportion of population every year [1-3]. The acute response of this injury leaves an individual prone to loss of function in the knee joint [4] while the long-term consequences of this injury are often associated with an early onset of degenerative changes in the joint $[5,6]$. Despite some controversies related to the long-term adverse effects of reconstructive surgery [7-9], still surgical reconstruction of ruptured ACL had remained a preferable choice for both the orthopaedic surgeons and the patients [10]. One of the reasons for the latter may be achieving of superior clinical outcomes of rehabilitation by the patients who have undergone ACL reconstruction compared to the clinical outcomes achieved by the patients whose ruptured ACLs were conservatively managed [11]. The significant role of well-organised and established rehabilitation programmes for the patients with ACL reconstruction is obvious from the scientific literature $[3,12,13]$ and patients have been reported to return to the respective sports (high demanding activities) within 6-month durations following robust rehabilitation programme in hospitals. However, in some cases patients following ACL reconstruction have not achieved optimal muscular power and knee stability in the knee joint $[14,15]$ which had led the patients to discontinue or change their preferred athletic activities following ACL reconstruction $[16,17]$. Rehabilitation programme following ACL reconstruction has seen deep scrutiny over the last 3 decades $[18,19]$; and the current advancements in ACL rehabilitation programme are based on extensive clinical research in evidence based practices [20]. Early weight bearing, an increased range of motion in the knee joint, improved muscular strength and enhanced neuromuscular coordination for the both the flexor and extensor musculatures of the knee joint have been reported essential components for successful rehabilitation of patients who had undergone ACL reconstruction [21]. Despite the extensive scrutiny, supervision and its associated components during ACL rehabilitation have not received robust attention in the literature and warrants further research.

In clinical trials carried out on the effects of supervision on the outcomes of ACL rehabilitation programmes, it was reported that patients in the fully-supervised rehabilitation programmes had attended more number of supervised physiotherapy visits in the hospital compared to the patients in non-supervised rehabilitation group [22]. In contrast, in other clinical trial, supervision was associated with the environment where rehabilitation programme of ACL was delivered [23]. Patients receiving rehabilitation programme within hospitals were categorised as 'supervised' while patients receiving rehabilitation programme in community were categorised as 'non-supervised'. To the authors' knowledge 'supervision during rehabilitation' has not been clearly defined during rehabilitation programmes following ACL reconstruction, therefore, the aim of this review was to appraise available literature and identify factors that might be considered important for supervision during rehabilitation sessions to the patients.

\section{Methods}

$\nabla$

A review of literature regarding 'supervision during ACL rehabilitation' was undertaken (Jan 2005 until December 2014). Searches in electronic database including AMED, BNI, CINAHL, EMBASE, Health Business Elite, HMIC, MEDLINE, and PsycINFO were carried out for 'supervision during ACL rehabilitation'. Keywords including ACL, levels of supervision, structured and unstructured rehabilitation were used to search for the literature. Keywords in similar theme were grouped with the word 'OR' operator while the results of different themes were combined using the word 'AND' operator to get the final number of published articles in this area. Each of the final identified manuscript was reviewed manually and its reference list was checked for additional and relevant information. The keyword searches and their results are shown in $\bullet$ Table 1 . The remaining process of scrutinizing trials for inclusion in this review is shown in a flow chart, Preferred Reporting Items for Systematic Reviews and Meta-Analyses (PRISMA), in O Fig. 1. The expertise of rehabilitation team member who were associated with rehabilitation of the patients recruited for a research programme, shared their personal view regarding the components of supervision during rehabilitation sessions in the hospital.

\section{Inclusion and exclusion criteria}

The inclusion criterion was limited to clinical trials carried out on the levels of supervision following ACL reconstruction. The search was limited to articles published in the English language from the year 2005 until the year 2014. Initially, all abstracts were reviewed by 2 independent reviewers (HD and AA) and were grouped into "relevant", "irrelevant" or "unsure" catego-

Table 1 Table showing database searches for the systematic review.

\begin{tabular}{|llr|}
\hline S/No & key words for searching in databases & Hits \\
\hline 1 & Anterior cruciate ligament & 31709 \\
\hline 2 & Supervised & 41298 \\
\hline 3 & Unsupervised & 15232 \\
\hline 4 & Hospital-managed & 147 \\
\hline 5 & ACL & 25686 \\
\hline 6 & Structured & 319323 \\
\hline 7 & 1 OR 5 & 41644 \\
\hline 8 & 2 OR 3 OR 4 OR 6 & 370112 \\
\hline 9 & 7 AND 8 & 230 \\
\hline
\end{tabular}




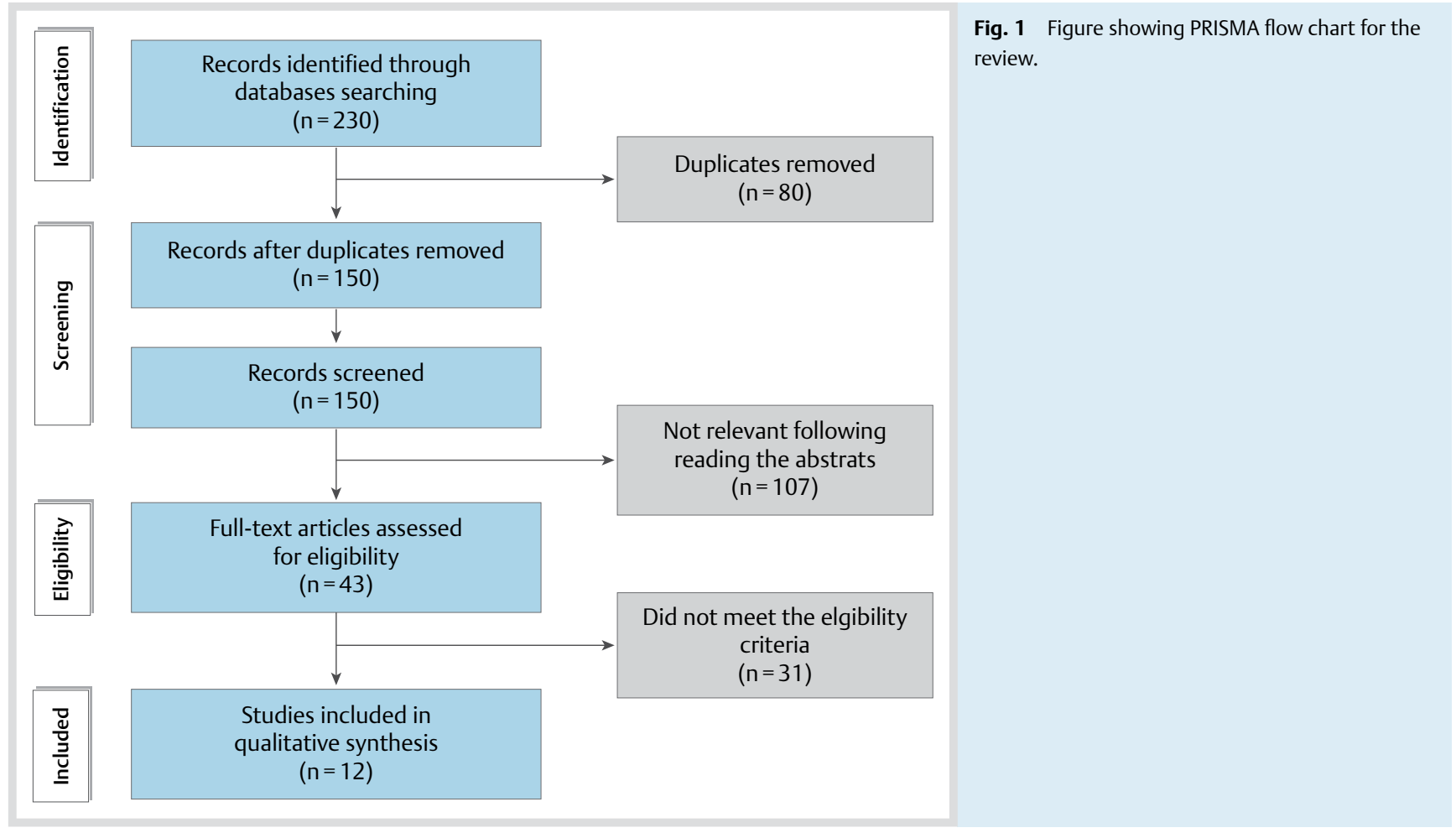

ries. In cases where the abstracts were not helpful, full manuscripts were reviewed before consensual allocation into the 3 categories of relevance.

\section{Results}

\section{$\nabla$}

A total to 230 articles were identified using the key words in the selected databases. Out of 230 articles, 80 were found duplicates leaving 150 eligible for this review. Abstracts of the remaining 150 manuscripts were studied by the authors and 107 articles were grouped into 'not relevant category'. Full text of the remaining 43 manuscripts were checked for eligibility criteria and 31 of the latter manuscripts did not fulfilled the inclusion and exclusion criteria, leaving a total of 12 articles eligible for this review (see $\bullet$ Table 2 for summary of the trials included in this review). Inconsistency in defining the term 'supervision during ACL rehabilitation' was found amongst the clinical trials carried out on supervised rehabilitation programme following ACL reconstruction. None of the clinical trials included in this review have clearly defined supervision during rehabilitation programme following ACL reconstruction. In some of the trials, rehabilitation programme delivered in different environments have been associated with supervision. Grant et al. [23], Beard and Dodd [24], Schenck et al. [25], Ugutmen et al. [26] and Ageberg et al. [27] associated supervision with environment and patients coming to hospitals were labelled as 'supervised rehabilitation group' and patients self-managing exercises at home were grouped into unsupervised rehabilitation category. The nature of supervision during ACL rehabilitation in these hospitals remained unclear from these trials. In contrast, Fischer et al. [28], Feller et al. [29], De Carlo et al. [30] and Hohmann et al. [22] associated supervision with the number of physiotherapy sessions received by the patients in hospital or other clinical settings included clinics. In a case report by Darain et al. [31], su- pervision during rehabilitation was associated with the quality time received by a patient from monitoring of physiotherapist in a hospital. Volumes and intensities of training during rehabilitation following ACL reconstruction had not received robust attention and none of the trials included in this review had associated these characteristics with supervision.

\section{Discussion \\ $\nabla$}

The aim of this review was to evaluate evidence regarding supervision during rehabilitation programme following ACL reconstruction and report factors that may be considered important while applying supervised rehabilitation sessions to the patients. The word 'supervision' during rehabilitation following ACL reconstruction has not clearly been defined in the clinical trials carried out on the effects of supervision on the outcomes of ACL rehabilitation. Supervision during rehabilitation following the latter condition has been differentiated from the unsupervised rehabilitation programmes in terms of environment where rehabilitation programme was delivered. In a clinical trial carried out by Grant et al. [23], patients coming to the hospital were categorised in supervised rehabilitation group while patients following rehabilitation programme in the community/ home were classified in non-supervised rehabilitation group. Similarly, in a randomised controlled trials carried out by Beard and Dodd [24], physiotherapy programme delivered in hospital were termed supervised rehabilitation programmes while rehabilitation programmes self-managed by the patients in community was categorised as non-supervised rehabilitation programme. Moreover, Schenck et al. [25] in a randomised controlled trial associated supervision with the environment and patients receiving physiotherapy sessions at hospital were grouped into supervised group and patients receiving physiotherapy sessions at clinics were labelled as unsupervised group. 
Table 2 Trials included in the review regarding supervision during ACL rehabilitation.

\begin{tabular}{|c|c|c|}
\hline Authors & Supervision during the trial & Findings \\
\hline $\begin{array}{l}\text { Schenck et al. } \\
1997\end{array}$ & $\begin{array}{l}\text { Supervision was associated with environment and the outcomes of home- } \\
\text { based rehabilitation programme were compared with the outcomes of } \\
\text { clinic-based rehabilitation programme. }\end{array}$ & $\begin{array}{l}\text { Patients in both the groups achieved statistically similar } \\
\text { outcomes. }\end{array}$ \\
\hline $\begin{array}{l}\text { Fischer et al. } \\
1997\end{array}$ & $\begin{array}{l}\text { Patients in home-based rehabilitation group attended } 6 \text { physiotherapy } \\
\text { sessions at the hospital while patients in clinic-based rehabilitation group } \\
\text { attended } 24 \text { physiotherapy session at the hospital. }\end{array}$ & $\begin{array}{l}\text { Patients in both groups showed similar outcomes on subjec- } \\
\text { tive, objective and functional outcome measures. }\end{array}$ \\
\hline $\begin{array}{l}\text { De Carlo and } \\
\text { Sell. } 1997\end{array}$ & $\begin{array}{l}\text { The effects of number and frequency of physiotherapy sessions in the } \\
\text { hospital were compared in patients who had undergone ACL reconstruc- } \\
\text { tive surgery. }\end{array}$ & $\begin{array}{l}\text { Patients in a structured physiotherapy programme with fewer } \\
\text { sessions achieved successful outcomes. }\end{array}$ \\
\hline $\begin{array}{l}\text { Treacy et al. } \\
1997\end{array}$ & $\begin{array}{l}\text { Patients were divided into compliant, minimal compliant and non-com- } \\
\text { pliant groups based on the number of physiotherapy sessions attended in } \\
\text { the hospital. }\end{array}$ & $\begin{array}{l}\text { No differences were observed amongst the patients in minimal } \\
\text { compliant and compliant groups. }\end{array}$ \\
\hline $\begin{array}{l}\text { Beard and } \\
\text { Dodd. } 1998\end{array}$ & $\begin{array}{l}\text { Home-based plus supervised physiotherapy rehabilitation programme } \\
\text { was compared with the outcomes of home-based programme alone after } \\
\text { ACL reconstruction. }\end{array}$ & $\begin{array}{l}\text { Patients in both groups showed significant improvement with } \\
\text { no differences between the groups. }\end{array}$ \\
\hline $\begin{array}{l}\text { Ageberg et al. } \\
2001\end{array}$ & $\begin{array}{l}\text { A 3-year longitudinal trial was carried out to compare the outcomes of } \\
\text { supervised and unsupervised training in clinical population who have } \\
\text { undergone ACL reconstruction. }\end{array}$ & $\begin{array}{l}\text { Regardless treatment pattern centre of pressure remained } \\
\text { higher in both the injured and non-injured legs. }\end{array}$ \\
\hline $\begin{array}{l}\text { Feller et al. } \\
2003\end{array}$ & $\begin{array}{l}\text { The level of supervision in the trial was determined by the number of } \\
\text { visits made by the patients to the hospital. }\end{array}$ & $\begin{array}{l}\text { Patients in minimal supervised group showed better Cincinnati } \\
\text { Knee Scores. }\end{array}$ \\
\hline $\begin{array}{l}\text { Grant et al. } \\
2005\end{array}$ & $\begin{array}{l}\text { Patients in less supervised group received rehabilitation programme } \\
\text { at home while patients at physical therapy supervised groups received } \\
\text { rehabilitation at physiotherapy clinics }\end{array}$ & $\begin{array}{l}\text { A significant number of patients in home-based rehabilitation } \\
\text { programme achieved better range of motion. }\end{array}$ \\
\hline $\begin{array}{l}\text { Ugutmen et al. } \\
2008\end{array}$ & $\begin{array}{l}\text { Patients in home-based rehabilitation were guided to similar component of } \\
\text { rehabilitation suggested to the patients in clinic-based rehabilitation group. }\end{array}$ & $\begin{array}{l}\text { Statistically similar outcomes were achieved by the patients in } \\
\text { both the groups }\end{array}$ \\
\hline $\begin{array}{l}\text { Grant and } \\
\text { Mohtadi } 2010\end{array}$ & $\begin{array}{l}\text { A follow-up study where patients were randomly allocated into physical } \\
\text { therapy supervised and home-based rehabilitation groups }\end{array}$ & $\begin{array}{l}\text { Patients in both the groups showed similar outcomes even } \\
\text { after 2- to 4-year following } \mathrm{ACL} \text { reconstruction }\end{array}$ \\
\hline $\begin{array}{l}\text { Hohmann et al. } \\
2011\end{array}$ & $\begin{array}{l}\text { Patients with ACL reconstruction following physiotherapy guided and } \\
\text { home-based unsupervised rehabilitation programmes were compared. }\end{array}$ & $\begin{array}{l}\text { No obvious benefits were reported for the physiotherapy } \\
\text { guided programme. }\end{array}$ \\
\hline $\begin{array}{l}\text { Darain et al. } \\
2014\end{array}$ & $\begin{array}{l}\text { A case study carried out on the amount of supervised time received by } \\
\text { the patient in a hospital during ACL rehabilitation. }\end{array}$ & $\begin{array}{l}\text { The patients visited the hospital } 15 \text { times being supervised } \\
\text { by physiotherapist with a duration of supervision between } \\
30-90 \text { min }\end{array}$ \\
\hline
\end{tabular}

Ugutmen et al. [26] carried out a randomised controlled trial on the effectiveness of hospital and community-based rehabilitation programmes and supervision was associated with the environment. In addition, Ageberg et al. [27] in a longitudinal controlled trial assessed the outcomes of supervised and unsupervised rehabilitation programme following ACL reconstruction. The patients in supervised group were monitored by the physiotherapists in the hospital while the patients in the unsupervised rehabilitation group were guided to do the same exercises at home. This indicated that attending physiotherapy sessions in hospitals were associated with supervision during rehabilitation programme following ACL reconstruction. One of the reasons for this might be the active involvement of rehabilitation team during rehabilitation programme delivered in hospital environment that ensures closely monitoring of rehabilitative activities and modifying intensities and volume of the exercise programmes according to the needs of patients. Such close monitoring of exercise programmes by members of rehabilitation is lacking in rehabilitative activities self-managed by the patients in community settings and they can modify intensities and volume of training according to their perceived needs and preferences.

In other trials, 'supervision' during ACL rehabilitation was associated with number of physiotherapy sessions attended in hospitals $[28,30]$. In the latter clinical trial, patients who attended 6 or 7 physiotherapy sessions were categorised as 'unsupervised' rehabilitation groups while patients who attended 20 physiotherapy sessions in the same hospital were catego- rised as supervised rehabilitation groups. Similarly, in clinical trial carried out by Hohmann et al. [22] the patients receiving rehabilitation programme in the hospital were categorised as a supervised rehabilitation group while patients self-managing rehabilitation programme in their homes were categorised unsupervised rehabilitation groups. Patients in the latter rehabilitation group were given a handout containing information about the whole rehabilitation programme followed by the patients in the supervised rehabilitation groups in outpatients department of the hospitals.

Rehabilitation programmes following ACL reconstruction are multifaceted and different implementation modes of the rehabilitation programmes have been reported in the literature $[3,23,29,32]$. This might be one the reasons that implementation of this programme does not requires closely monitoring from the rehabilitation team on daily basis [33]. However, the obvious advantages of rehabilitation programmes delivered in well-controlled environment over rehabilitation programmes self-managed by the patients in community have been reported in clinical trials carried out on ACL reconstruction indicating the significant role of supervision. Despite the latter fact, a uniform rehabilitation programme following ACL reconstruction was not reported in the literature [31]. This issue was observed while carrying out this review and only few studies were found where supervision was discussed. However, still it was defined that how a supervise programme will be differentiated from a non-supervised rehabilitation programme following ACL reconstruction. 


\section{Conclusion}

Based on the previous clinical trials included in this review on ACL rehabilitation, it can be concluded that 'supervision' during $A C L$ is multifactorial and the presence of some of the elements may be associated with supervision. Presence of physiotherapist and well controlled environment are major factors that may be associated with supervision during rehabilitation programme following $\mathrm{ACL}$ reconstruction.

\section{Recommendations}

$\nabla$

- Supervision during the rehabilitation is subjective in nature and the level of supervision may be decided based on the individual patient's capabilities to follow the programme.

- Environment and interaction of physiotherapists with patients are important components of supervision. Both the factors may be considered carefully while suggesting any mode of treatment to patients.

\section{Conflict of Interest}

The authors declare no conflicts of interest.

\section{References}

1 Granan L-P, Bahr R, Steindal K et al. Development of a national cruciate ligament surgery registry: the Norwegian National Knee Ligament Registry. The American Journal of Sports Medicine 2008; 36: 308-315

2 Gianotti SM, Marshall SW, Hume PA et al. Incidence of anterior cruciate ligament injury and other knee ligament injuries: A national population-based study. Journal of Science and Medicine in Sport 2009; 12: 622-627

3 Arna Risberg M, Lewek M, Snyder-Mackler L. A systematic review of evidence for anterior cruciate ligament rehabilitation: how much and what type? Physical Therapy in Sport 2004; 5: 125-145

4 Stucki G, Stier-Jarmer M, Grill E et al. Rationale and principles of early rehabilitation care after an acute injury or illness. Disability \& Rehabilitation 2005; 27: 353-359

5 Mock C, Cherian MN. The global burden of musculoskeletal injuries: challenges and solutions. Clinical orthopaedics and related research 2008; 466: 2306-2316

6 Lohmander LS, Englund PM, Dahl LL et al. The long-term consequence of anterior cruciate ligament and meniscus injuries: osteoarthritis. Am J Sports Med 2007; 35: 1756-1769

7 Øiestad BE, Holm I, Engebretsen L et al. The prevalence of patellofemoral osteoarthritis 12 years after anterior cruciate ligament reconstruction. Knee Surgery, Sports Traumatology, Arthroscopy 2013; 21: 942-949

8 Øiestad BE, Holm I, Aune AK et al. Knee function and prevalence of knee osteoarthritis after anterior cruciate ligament reconstruction: a prospective study with 10 to 15 years of follow-up. The American Journal of Sports Medicine 2010; 38: 2201-2210

9 Spindler KP, Huston LJ, Wright RW et al. The prognosis and predictors of sports function and activity at minimum 6 years after anterior cruciate ligament reconstruction: a population cohort study. The American Journal of Sports Medicine 2011; 39: 348-359

$10 \mathrm{Fu} F \mathrm{FH}$, Bennett CH, Ma B et al. Current trends in anterior cruciate ligament reconstruction: part ii. operative procedures and clinical correlations. The American Journal of Sports Medicine 2000; 28: 124-130

11 Strehl A, Eggli S. The value of conservative treatment in ruptures of the anterior cruciate ligament (ACL). Journal of Trauma and Acute Care Surgery 2007; 62: 1159-1162

12 Van Grinsven S, Van Cingel REH, Holla CJM et al. Evidence-based rehabilitation following anterior cruciate ligament reconstruction. Knee Surgery, Sports Traumatology, Arthroscopy 2010; 18: 1128-1144

13 Ayeni OR, Evaniew N, Ogilvie $R$ et al. Evidence-Based practice to improve outcomes of anterior cruciate ligament reconstruction. Clinics in sports medicine $2013 ; 32: 71-80$
14 Loh JC, Fukuda Y, Tsuda E et al. Knee stability and graft function following anterior cruciate ligament reconstruction: Comparison between 11 o'clock and 10 o'clock femoral tunnel placement. Arthroscopy: The Journal of Arthroscopic \& Related Surgery 2003; 19: 297-304

15 Lohmander LS, Östenberg A, Englund M et al. High prevalence of knee osteoarthritis, pain, and functional limitations in female soccer players twelve years after anterior cruciate ligament injury. Arthritis \& Rheumatism 2004; 50: 3145-3152

16 Ardern $C L$, Webster KE, Taylor NF et al. Return to the preinjury level of competitive sport after anterior cruciate ligament reconstruction surgery: two-thirds of patients have not returned by 12 months after surgery. The American Journal of Sports Medicine 2011; 39: 538-543

17 Kvist J. Rehabilitation following anterior cruciate ligament injury. Sports Medicine 2004; 34: 269-280

18 Biggs A, Jenkins WL, Urch SE et al. Rehabilitation for patients following acl reconstruction: a knee symmetry model. North American Journal Of Sports Physical Therapy: NAJSPT 2009; 4: 2-12

19 Shelbourne KD, Klotz C. What I have learned about the ACL: utilizing a progressive rehabilitation scheme to achieve total knee symmetry after anterior cruciate ligament reconstruction. Journal of Orthopaedic Science 2006; 11: 318-325

20 Wilk KE, Macrina LC, Cain EL et al. Recent advances in the rehabilitation of anterior cruciate ligament injuries. The Journal of orthopaedic and sports physical therapy 2012; 42: 153-171

21 Wright RW, Preston E, Fleming $B C$ et al. A systematic review of anterior cruciate ligament reconstruction rehabilitation: part I: continuous passive motion, early weight bearing, postoperative bracing, and home-based rehabilitation. The Journal Of Knee Surgery 2008; 21: 217-224

22 Hohmann E, Tetsworth $K$, Bryant A. Physiotherapy-guided versus home-based, unsupervised rehabilitation in isolated anterior cruciate injuries following surgical reconstruction. Knee Surgery, Sports Traumatology, Arthroscopy: Official Journal Of The ESSKA 2011; 19: $1158-1167$

23 Grant JA, Mohtadi NGH, Maitland ME et al. Comparison of home versus physical therapy-supervised rehabilitation programs after anterior cruciate ligament reconstruction a randomized clinical trial. American Journal of Sports Medicine 2005; 33: 1288-1297

24 Beard DJ, Dodd CA. Home or supervised rehabilitation following anterior cruciate ligament reconstruction: a randomized controlled trial. The Journal of orthopaedic and sports physical therapy 1998; 27: 134-143

25 Schenck RC, Blaschak MJ, Lance ED et al. A prospective outcome study of rehabilitation programs and anterior cruciate ligament reconstruction. Arthroscopy: The Journal Of Arthroscopic \& Related Surgery: Official Publication Of The Arthroscopy Association Of North America And The International Arthroscopy Association 1997; 13: 285-290

26 Ugutmen E, Ozkan K, Kilincoglu $V$ et al. Anterior cruciate ligament reconstruction by using otogenous [correction of otogeneous] hamstring tendons with home-based rehabilitation. The Journal of international medical research 2008; 36: 253-259

27 Ageberg E, Zätterström R, Moritz $U$ et al. Influence of supervised and nonsupervised training on postural control after an acute anterior cruciate ligament rupture: a three-year longitudinal prospective study. Journal of Orthopaedic \& Sports Physical Therapy 2001; 31: 632-644

28 Fischer DA, Tewes DP, Boyd JL et al. Home based rehabilitation for anterior cruciate ligament reconstruction. Clinical orthopaedics and related research 1998; 347:194-199

29 Feller JA, Webster KE, Taylor NF et al. Effect of physiotherapy attendance on outcome after anterior cruciate ligament reconstruction: a pilot study. British journal of sports medicine 2004; 38: 74-77

30 De Carlo MS, Sell KE. The effects of the number and frequency of physical therapy treatments on selected outcomes of treatment in patients with anterior cruciate ligament reconstruction. Journal of Orthopaedic \& Sports Physical Therapy 1997; 26: 332-339

31 Darain H, Alkitani A, Yates C et al. Antecedent anterior cruciate ligament reconstruction surgery and optimal duration of supervised physiotherapy. Journal of back and musculoskeletal rehabilitation 2014; 28: 877-882

32 Grant JA, Mohtadi NGH. Two- to 4-year follow-up to a comparison of home versus physical therapy-supervised rehabilitation programs after anterior cruciate ligament reconstruction. American Journal of Sports Medicine 2010; 38: 1389-1394

33 Treacy SH, Barron OA, Brunet ME et al. Assessing the need for extensive supervised rehabilitation following arthroscopic ACL reconstruction. American journal of orthopedics (Belle Mead, N.J.) 1997; 26: 25-29 